\title{
Representation of Males and Females in Myanmar Culture through a Selection of Myanmar Literary Works in English
}

\author{
Tin Moe $\mathrm{Yi}^{1}$ \\ ${ }^{1}$ English Professional Development Programme, School of Liberal Arts, Mae Fah Luang University, Thailand \\ Correspondence: Tin Moe Yi, English Professional Development Programme of Mae Fah Luang University, \\ Thailand, Tel: 66-93-227-8568. E-mail: tinmoeyi73@gmail.com
}

\author{
Received: April 11, 2016 Accepted: April 24, 2016 Online Published: May 9, 2016 \\ doi:10.5539/ach.v8n2p32 URL: http://dx.doi.org/10.5539/ach.v8n2p32
}

\begin{abstract}
In Myanmar, although men and women have equal rights under the customary law, conservative cultural belief prevents to enjoy these rights between men and women. Therefore men are still superior and women are subordinate in Myanmar society. To reach a better understanding of whether equality exists between men and women in Myanmar society, a particular type of literary work which is reflection of Myanmar culture can be explored. Therefore, Myanmar short stories, written originally in English by Myanmar author Daw Khin Myo Chit and the selection of Myanmar short stories written originally in Myanmar by various kinds of Myanmar authors but translated into English by Myanmar writer Ma Thanegi, are chosen to be investigated. The aim of the present study is to investigate the way in which males and females are represented in Myanmar short stories which reflect Myanmar culture. Gender analysis by Khurshid, Gillani, and Hashmi (2010) is conducted to analyze the data. The quantitative and qualitative methods were used to analyze short stories. It is found that the data found in Daw Khin Myo Chit's short stories and Ma Thanegi's translated works were the same. The results showed that there is no significant difference between males and females except occupational roles. It can also be observed that in analyzing Myanmar short stories, although women play the important roles as equal as men in most cases, women are still inferior rather than men according to Myanmar culture and Myanmar tradition.
\end{abstract}

Keywords: culture, equality, gender analysis, literary works, representation, short stories

\section{Introduction}

Gender issue is prominent in different countries in the world; however, little has been done to investigate gender roles and representations in Myanmar, a Southeast Asian country. According to Myanmar custom and tradition, women, rather than men, are expected to take care of their families (Department for International Development [DFID] Myanmar operational plan 2011 -gender annex, 2011). Yet at the same time, women have the right to do as they wish in the economy of their families. Although they do not take part in all family affairs, they can act as advisors to their husbands, or people to be consulted before important decisions are made (Minn, 2014). In education, girls and boys have equal right to enroll in the schools. In general, women have higher education and higher degrees than men. Although the number of educated women is higher than that of educated men, women have less chance to join in the labour force (Interim country partnership strategy, Myanmar, 2012-2014). In Buddhism, the main religion in Myanmar, nuns and women have no right to offer gold leaves to the pagoda; instead, they have to ask men to do so. Women are forbidden by Myanmar tradition and culture to participate in some ceremonies and to enter some parts of a temple and a monastery (Belak, 2002). Therefore, women are given more rights in some cases and they are inferior in some cases.

In gender, discourse, and displacement, Ikeya (cited in Ho, 2011) has also pointed out that the stereotype of Myanmar women's high status had been spread in popular and scholar discourses, but it had been ignored. Therefore, by the end of twentieth century, representation of Myanmar women had disappeared. However, in 2007 according to the customary law expressed in Social Institute and Gender Index (SIGI, 2015), Myanmar government reported that both men and women are given equal rights. Furthermore, Human Rights Education Institute of Myanmar (HREIM) also attempts to improve gender equality among Myanmar people by raising the awareness of equality between males and females in the social context (DFID Myanmar operational plan 2011 -gender annex, 2011). In 2013, through the National Strategic Plan for the Advancement of Women (NSPAW), Myanmar government has attempted to develop women's rights in Myanmar through the creation of enabling 
systems, structures and practices: sexuality, men's violence against women, and women's participation in making decision such as in peace-processes and in public and in political affairs (Thein, 2015). But there is still discrimation between males and female in some cases as stated before.

Generally, literary works usually reflect a number of different aspects of a society and its culture. For this reason, I, the researcher, attempt to investigate gender characteristics and representations in Myanmar socio-cultural contexts by investigating a selection of literary works, namely, short stories. In the selection, one is a book of 23 short stories written originally in English during the post-colonial period by the author Daw Khin Myo Chit (Chit, 2004) and (Daw, 2005). The other is a compilation of colonial and post-colonial 25-short stories written originally in Myanmar language by various authors and later translated into English by Ma Thanegi (Thanegi, 2009). These short stories are based on Myanmar authentic culture and Myanmar real society. Therefore, this study attempts to examine men and women in Myanmar short stories in terms of their equality, qualities and capacity in society, to investigate how the author and translator portray men and women in the literary works to represent Myanmar society and Myanmar culture.

\subsection{Statement of the Problem}

Like the other countries, the communities in Myanmar try to raise the social standard based on gender. According to the customary law expressed in Social Institute and Gender Index, the government reported in 2007 that both men and women are given the equal rights to get the inheritance (Information about variable and data sources for 2014 SIGI, SIGI (2015)). Although there is equal right between men and women under the government law in Myanmar, there is still discrimination between them due to the customary and social tradition In the public policy in Myanmar, the abilities of men and women to enjoy the equal rights are influenced by conservative cultural beliefs and practices. In the duties as citizenship, although both men and women are in the higher positions, mostly are the men and man's decision-making is emphasized in the higher position. Minn (2014) adds that Myanmar women have the abilities but they are prohibited to express their opinion and they have no right to do so. It is believed that men can make decision better than women. However, in the social situation, there is practical equality between men and women. Therefore, Myanmar women feel satisfied as they have freedom, independence and rights which are equal to men (Legal Issues on Myanmar Journal, 2011, August) volume 9 .

It is said that although both men and women have equal rights in Myanmar society, men are respected by women according to Myanmar culture and Myanmar tradition. However, gender discrimination is a very subtle social phenomenon and a better understanding of this phenomenon may not be achieved without a course to literary work, which is a reflection of its society. Therefore, Myanmar short stories which reflect Myanmar authentic culture are chosen to see how the gender discrimination appears in Myanmar society.

\subsection{Related Literatures}

Representations of males and females can be studied through works of fiction. Ottosson and Cheng (2012) analyzed gender representation in the movie "Sex and the City 1 and 2"which has the influence of west culture. By using discourse analysis, the researchers explored whether or not the characters in the movies challenged patriarchal privilege. In this fiction, the results show that from the discourse analysis, women are portrayed as the negative aspect of women's portrayal than positive. And when Helleis (2004) analyzes one hundred stories written by different authors through the content analysis and descriptive statistics analysis, the results show that male dominates and female is subordinate in the stories. In investigating the children books chosen from the library in a small Canadian city, MacArthur and Poulin (2011) used descriptive statistic and student's $t$ test to analyze the books. Their results show that there is no equality between males and females and females are inferior to males in this research.

In studying the previous researches that focus on the gender representation, it can be found that there is no equality between males and females and men are superior and women are inferior. Therefore the present study is conducted to investigate how Myanmar authors represent males and females in their literary works to evaluate whether there is gender equality or not in Myanmar society.

\subsection{Research Questions}

1) How do the authors convey representation of males and females that reflects Myanmar society in their writings (characters by sex, occupations assigned to males and females, and the occurrence of activities assigned to males and females)? 
2) How do the authors present gender stereotypes in their short stories and is there a relationship between gender and the description such as having career or not; active or passive; aggressive or nurturing; being outdoors or indoor locations; rescuing others or being in needed have rescue; emotional or unemotional?

\subsection{Purpose of the Study}

The aim of the study is to investigate, using gender analysis, the way in which gender is represented in Myanmar short stories and what Myanmar gender-related sociocultural features are reflected by such literary representation.

The objectives of the present study are:

1) To explore men's and women's social qualities and capacity through Myanmar short stories; and

2) To investigate how the authors represent the male and female characters in the short stories.

\subsection{Significance of the Study}

This study will be significant for

1) Teachers of literature who can deepen their understanding of the social value of literary works;

2) Scholars who are interested in the gender status and role in Myanmar Society as reflected in literary works; and

3) Myanmar writers written in English to reflect Myanmar culture.

Therefore, it is expected that the current study would increase an awareness of the roles, equality and rights of Myanmar males and females under the customary law which is effective during the colonial and post-colonial periods. In addition to its contribution to literature studies, this study is an attempt to disseminate knowledge of Myanmar culture and society to the outside world.

\subsection{Gaps of Knowledge}

There are also many research studies that have been done on gender representation in literature to examine gender equality. However, no serious attempt has been made to examine gender roles and representation in Myanmar society and Myanmar culture through literary works written by Myanmar authors in English. The present study analyzes Myanmar short stories written in English, to establish and discuss socially gender-related patterns as reflected through the selected pieces of literature. In studying researches about the gender role written by many researchers from different countries, it is found mostly that women are inferior to men. Therefore, this research attempts to analyze how Myanmar authors represent the gender role in their literary works.

\section{Method}

This study is based on quantitative and qualitative approaches. By using gender analysis, the data is collected to solve the research questions. In undertaking this research, it is discovered about how the social roles, capabilities and traits of men and women are depicted in Myanmar short stories.

Quantitative method is used to count and record the frequency of characters by sex, occupation, activities and stereotyping assigned to males and females to examine whether there is equality or inequality between males and females to some extent. The percentages are calculated for descriptive statistical analysis.

Qualitative analysis is made through close and critical reading of all short stories and the data found are explained and discussed by using gender analysis to check whether there is gender discrimination and gender stereotypes, and how males and females are represented in short stories.

Gender analysis is performed to collect the data for this study. According to Khurshid, Gillani, and Hashmi (2010), gender analysis is carried out by three criteria:

1) Invisibility and Non-recognition - the ratio of character by sex

2) Gender discrimination of labour

(a) Occupations assigned to males and females

(b) Activities associated with the occurrence of males and females

3) Stereotypes of femininity / Masculinity attributes assigned to males and females characters under broad categories of intellect, character and feelings

\subsection{Selection of Short Stories}

In this study, some selected Myanmar short stories are focused. The selected short stories to analyze in this study are drawn from "the 13 carat diamond and other stories" (English version) and "her infinite variety and other 
stories" (English version) which are 23-short stories written originally in English by Daw Khin Myo Chit and selected 25- Myanmar short stories written originally in Myanmar by various kinds of Myanmar authors which are translated from Myanmar into English by Ma Thanegi. These total 48-short stories have been chosen because of their great popularity and their reflection of authentic Myanmar culture.

\subsection{Data Collection Procedure}

To investigate representation of males and females in Myanmar short stories under study, both quantitative and qualitative methods are used. Each story from each book is read page by page to determine whether any references to male and female characters are presented in short stories. There are two main sets of categories in collecting data - one for originally in English and the other for translation of Myanmar short stories into English.

\subsection{Data Analysis}

The data analysis for Myanmar short stories is carried out according to the following categories,

(a) Sex ratio of characters by sex

(b) Occupations assigned to males and females

(c) Activities assigned to males and females

(d) Stereotypes of male and female representation

At first the frequencies of the categories mentioned above are counted and percentages are calculated in the quantitative analysis. Then the data obtained are explained and discussed how males and females are represented in qualitative analysis.

\section{Results}

By using gender analysis, the data are collected and analyzed as the followings,

\subsection{Analyzing Sex Ratio of Characters by Sex}

Table 1 shows that the frequency of characters by sex in overall short stories (23 short stories) written by Daw Khin Myo Chit and the frequency of overall short stories (25 short stories) written by various kinds of Myanmar authors translated into English by Ma Thanegi.

Table 1. Frequency of character by sex in Daw Khin Myo's short stories and Ma Thanegi's translated works

\begin{tabular}{lcc}
\hline \multicolumn{1}{c}{ Nature of Characters } & Daw Khin Myo Chit's & Ma Thanegi's \\
\hline Male & $51 \%(1630)$ & $47 \%(1396)$ \\
Female & $49 \%(1585)$ & $53 \%(1570)$ \\
Total & $100 \%$ & $100 \%$ \\
\hline
\end{tabular}

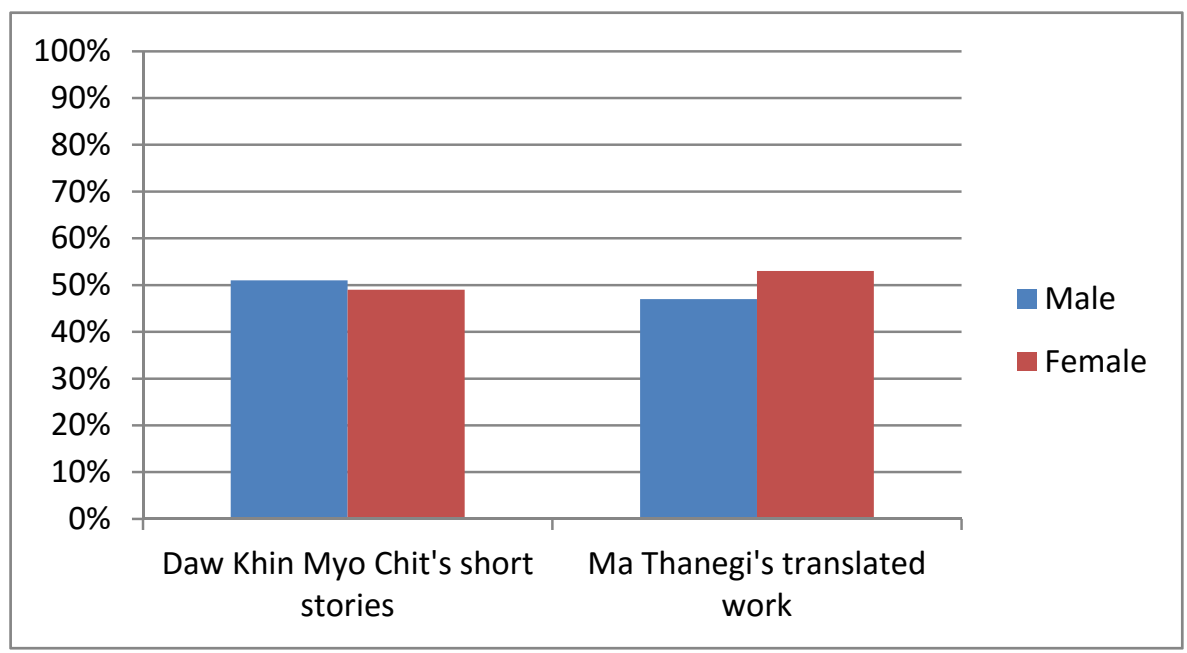

Figure1. Frequency of characters by sex in Daw Khin Myo Chit"s Stories and Ma Thanegi's translated works 
Table 1 shows that the number of male characters by sex is $1630(51 \%)$ and that of the female characters by sex is $1585(49 \%)$ and the frequency of males is slightly higher than females in Daw Khin Myo Chit's short stories while the number of male characters by sex is $1396(47 \%)$ and the number of female characters by sex is 1570 $(53 \%)$ and the frequency of female characters is slightly higher than males in Ma Thanegi's translated works. It is found that there is no significant difference between males and females in the two books.

\subsection{Analyzing Occupations Assigned to Males and Females}

The results found from analysing occupations assigned to males and females from the two books of selected short stories are shown in table 2.

Table 2. Frequency of occupations in Daw Khin Myo Chit's short stories and Ma Thanegi's translated works

\begin{tabular}{lll}
\hline Nature of Characters & Daw Khin Myo Chit's & Ma Thanegi's \\
\hline Male & $79 \%(213)$ & $80 \%(117)$ \\
Female & $21 \%(58)$ & $20 \%(29)$ \\
Total & $100 \%$ & $100 \%$ \\
\hline
\end{tabular}

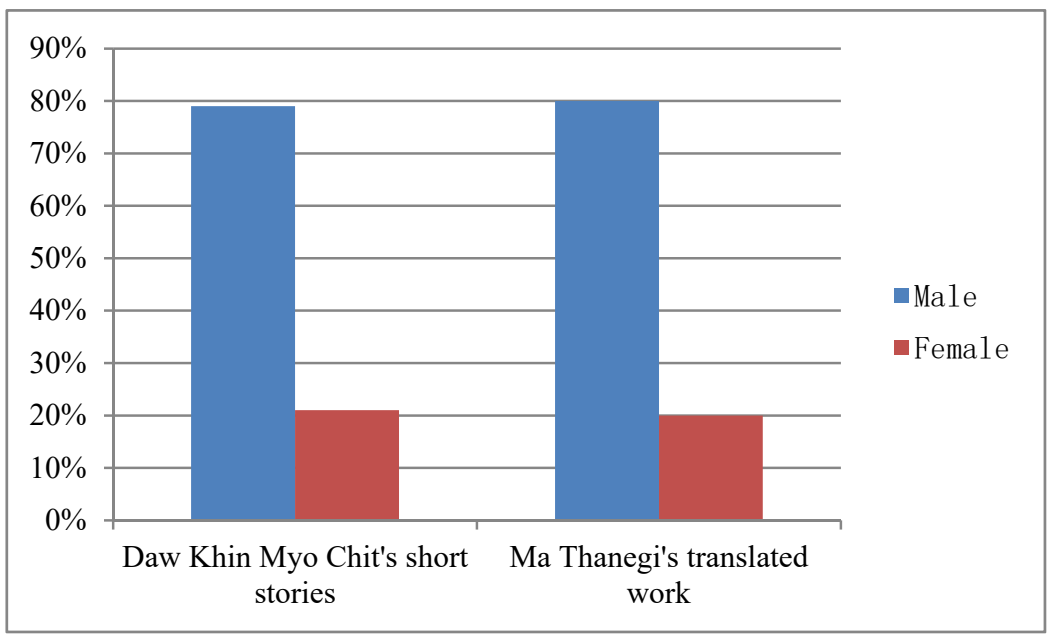

Figure 2. Frequency of occupations in Daw Khin Myo Chit's short stories and Ma Thanegi's translated works

Table 2 shows that the number of occupation assigned to males is 213 occupations (79\%) and that of occupations assigned to females is $58(21 \%)$ and so the frequency of occupations assigned to males is mostly higher than that of females assigned to females in Daw Khin Myo Chit's short stories. In Ma Thanegi's tramslated works, the number of occupations assigned to males is 117 (80\%) and the number of occupations assigned to females is 29 $(20 \%)$, and the frequency of occupations assigned to males is absolutely higher than that assigned to females. Therefore, it can be said that there is significant difference between the occupations assigned to males and the occupations assigned to females. It is found that the frequency of occupations assigned to males is significantly higher than that assigned to females in the two books.

\subsection{Analyzing the Activities Assigned to Males and Females}

Table 3 shows the activities assigned to males and females in Daw Khin Myo Chit's 23 short stories written originally in English and Ma Thanegi's translated works of 25 short stories.

Table 3. Activities found in Daw Khin Myo Chit's short stories and Ma Thanegi's translated works

\begin{tabular}{lll}
\hline Nature of Characters & Daw Khin Myo Chit's & Ma Thanegi's \\
\hline Male & $52 \%(245)$ & $46 \%(244)$ \\
Female & $48 \%(225)$ & $54 \%(286)$ \\
Total & $100 \%$ & $100 \%$ \\
\hline
\end{tabular}




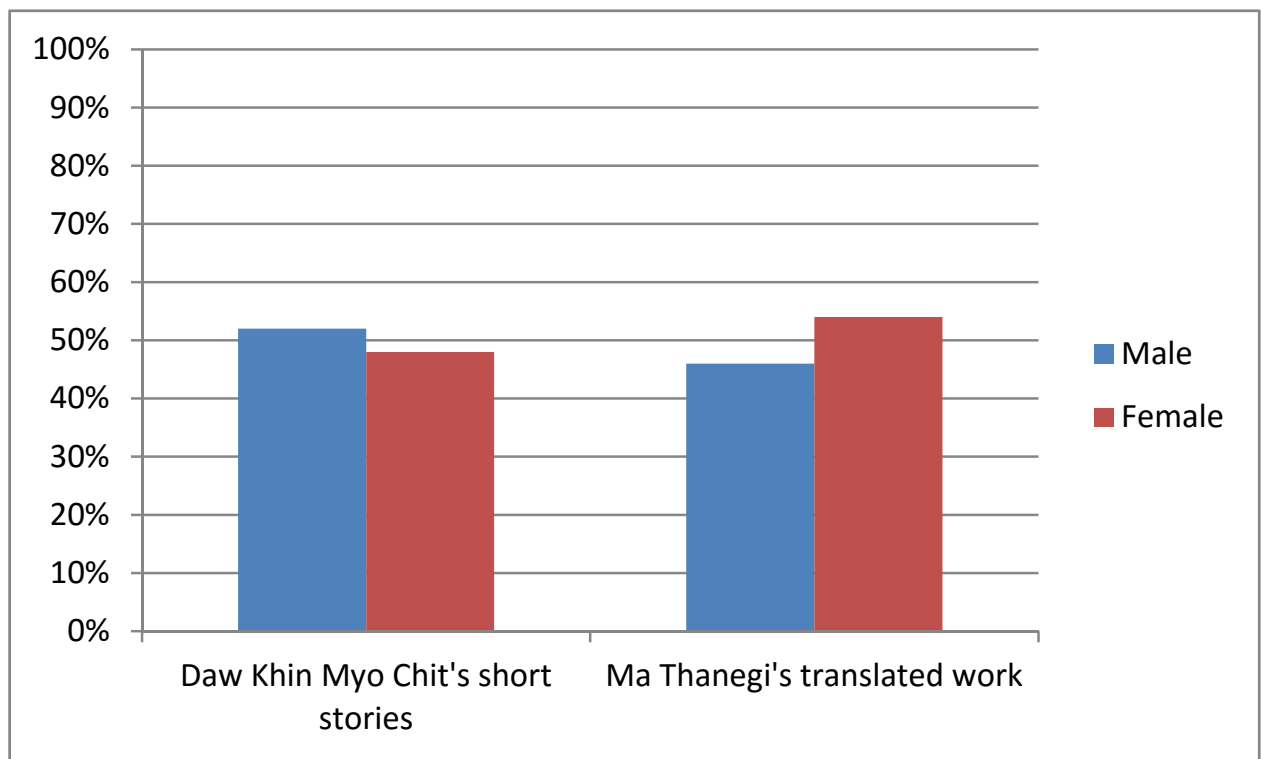

Figure 3. Activities found in Daw Khin Myo's short stories and Ma Thanegi's translated works

According to the table 3, the numbers of activities assigned to males and the activities assigned to females are approximately the same $245(52 \%)$ and $225(48 \%)$ respectively, and the frequency of males' activities is slightly higher than that of females in Daw Khin Myo Chit's short stories. Similarly, the numbers of the activities assigned to males and females are $244(46 \%)$ and $286(54 \%)$ respectively and the activities assigned to females are slightly more than that assigned to males in Ma Thanegi's translated works. So the result is that there is no significant difference between males and female in the activities of both of the books. However, in Daw Khin Myo Chit's short stories, the activities assigned to males are inconsiderably higher than that of females while in Ma Thanegi's translated works, the activities assigned to females are slightly higher than that of males.

\subsection{Stereotype of Male and Female Representation}

Table 4 indicates that the overall stereotyped representation of males and females from the two books. According to Paynter (2011), there are six categories and each category is analyzed for gender stereotyping.

Table 4. Stereotype of male and female representation in the short stories

\begin{tabular}{llllll}
\hline Category & Stereotyping & \multicolumn{2}{l}{ Daw Khin Myo Chit's } & \multicolumn{2}{l}{ Ma Thanegi's } \\
\cline { 3 - 6 } & & Male & Female & Male & Female \\
\hline 1 & Career option and division of labour & $79 \%(210)$ & $21 \%(56)$ & $82 \%(122)$ & $18 \%(26)$ \\
2 & a. Aggressive behavior & $68 \%(75)$ & $32 \%(36)$ & $50 \%(57)$ & $50 \%(58)$ \\
& b. Nurturing behaviour & $46 \%(39)$ & $54 \%(46)$ & $26 \%(27)$ & $74 \%(77)$ \\
3 & a. Active behavior & $65 \%(110)$ & $35 \%(60)$ & $68 \%(109)$ & $32 \%(52)$ \\
& b.Passive behaviour & $48 \%(50)$ & $52 \%(55)$ & $36 \%(54)$ & $64 \%(96)$ \\
4 & a. Indoor locations & $39 \%(9)$ & $61 \%(14)$ & $33 \%(3)$ & $67 \%(6)$ \\
5 & b. Outdoor locations & $66 \%(23)$ & $34 \%(12)$ & $59 \%(22)$ & $41 \%(15)$ \\
& a. Rescuing and helping behaviour & $62 \%(24)$ & $38 \%(15)$ & $73 \%(24)$ & $27 \%(9)$ \\
6 & b. Being rescued and being helped & $37 \%(7)$ & $63 \%(12)$ & $30 \%(3)$ & $70 \%(7)$ \\
& Emotion & $38 \%(48)$ & $62 \%(80)$ & $37 \%(26)$ & $63 \%(44)$ \\
\hline
\end{tabular}




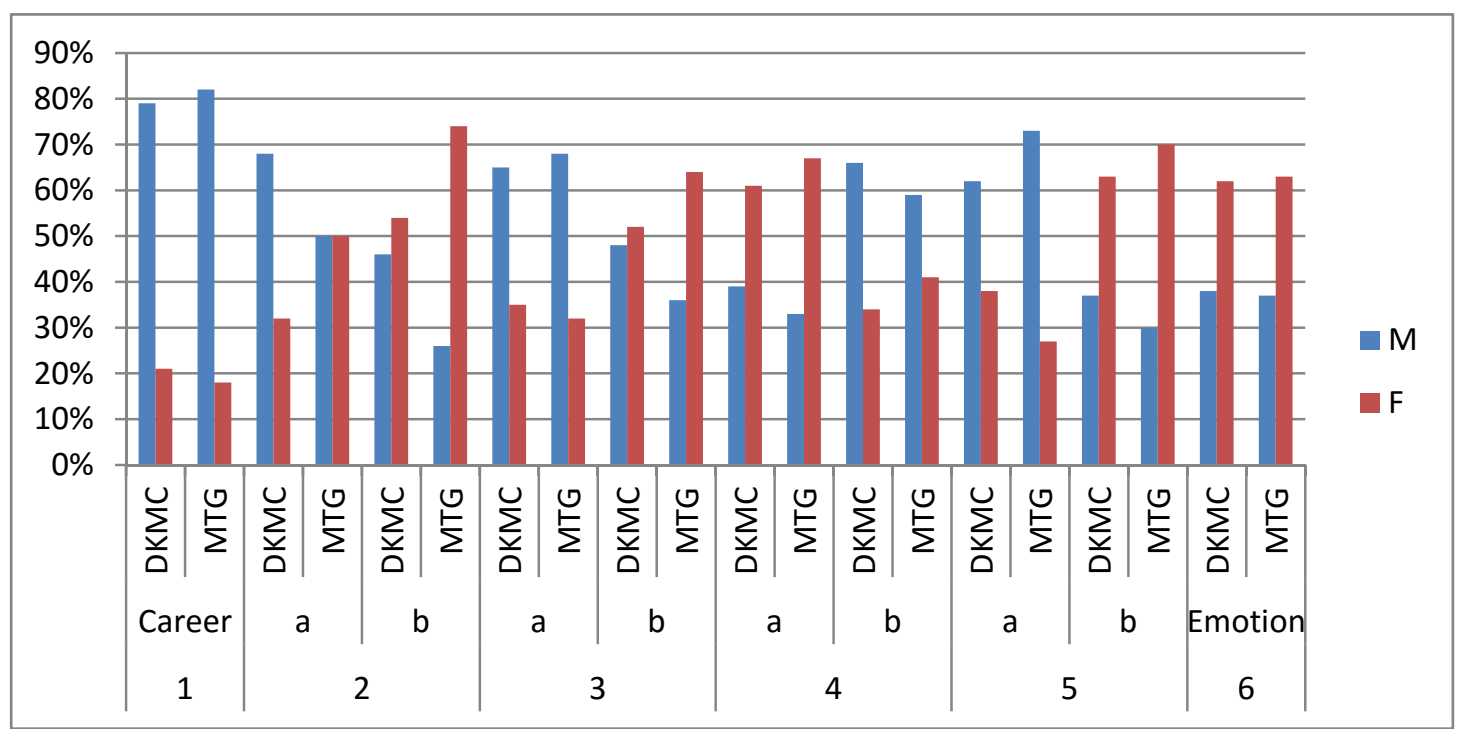

Figure 4. Stereotype of male and female representation in Daw Khin Myo Chit's short stories and Ma Thangi's translated works

As table 4 mentioned, in the career option and division of labour, the frequency of males is $210(79 \%)$ and that of females is $56(21 \%)$ in Daw Khin Myo Chit's short stories and $122(82 \%)$ for males and $26(18 \%)$ for females in Ma Thanegi's translated works respectively. So in this category, the frequency of males is mostly higher than that of females in the two books.

In the aggressive behavior, the number of males is $75(68 \%)$ and that of females is $36(32 \%)$ and it is higher for men than women in Daw Khin Myo Chit's short stories. On the other hand, the frequencies of males and females are the same $57(50 \%)$ and $58(50 \%)$ respectively and there is no difference between males and females for this aggressive behavior in Ma Thanegi's translated works. In the nurturing behavior, the numbers of male and female characters are $39(46 \%)$ and $46(54 \%)$ and the frequency of female characters is slightly higher than that of male characters in Daw Khin Myo Chit's short stories. In Ma Thanegi's translated works, the numbers of males and females are $27(26 \%)$ and $77(74 \%)$ respectively and so the frequency of female characters is mostly higher than that of male characters in this category of her translated work. However, it can be said that the female characters have more nurturing behavior than the male character in the two books.

In the active behavior, the number of males is $110(65 \%)$ and females 60 (35\%) in Daw Khin Myo Chit's short stories and males $109(68 \%)$ and $52(32 \%)$ in Ma Thanegi's translated works respectively. So in this active behavior, the frequency of male characters is higher than that of females in both of the books and the results are the same. In the passive behavior, the numbers of males and females are $50(48 \%)$ and $55(52 \%)$ and female characters are slightly higher than male characters in Daw Khin Myo Chit's short stories. In Ma Thanegi's translated works, the frequency of females $96(64 \%)$ is higher than that of males $54(36 \%)$. Therefore, the frequency of female characters is more than that of males in the passive bahaviour of the two books.

In the indoor locations, the numbers of males and females are $9(39 \%)$ and $14(61 \%)$ in Daw Khin Myo Chit's short stories and $3(33 \%)$ and $6(67 \%)$ in Ma Thanegi's translated works respectively. It is found that the frequency of males is lower than that of females in the indoor locations in both of the books. In contrast, in the outdoor locations, the numbers of males and females are $23(66 \%)$ and $12(34 \%)$ in Daw KhinMyo Chit's short stories and $22(59 \%)$ and $15(41 \%)$ in Ma Thangi's translated works. The result of outdoor locations is that the frequency of males is higher than that of females in the two books.

In helping behavior, the numbers of males and females are $24(62 \%)$ and $15(38 \%)$ in Daw Khin Myo Chit's short stories and $24(73 \%)$ and $9(27 \%)$ in Ma Thanegi's translated works. The result shows that frequency of males is higher than that of females in both of the books. On the other hand, in "being helped behavior" category, the frequency of females is higher than that of males in Daw Khin Myo Chit's short stories, which have 7 (37\%) for males and 12 (63) for females, and Ma Thanegi's translated works which have $3(30 \%)$ for males and 7 (70\%) for females respectively. 
In "emotion" which is the last category, the number of males is $48(38 \%)$ and that of females is $80(62 \%)$ in Daw Khin Myo Chit's short stories. In Ma Thanegi's translated works, the number of males is $26(37 \%)$ and females $44(63 \%)$. It can be found in both Daw Khin Myo Chit's short stories and Ma Thanegi's translated works that the frequency of females is higher than that of males in this category

Therefore table 4 indicates that although there is difference between males and females in each category (1-6), the same results are found in the two books, i.e. if the frequency of males is higher than females in any category in one book, the result of another book is same that the frequency of males is also higher that that of females in that category.

\section{Discussion}

In this attempt to investigate the representation of males and females in Myanmar short stories, the following categories are examined to solve the research questions. Categories (4.1 to 4.3) answer research question 1 and category 4.4 answers research question 2 .

\subsection{Characters by Sex}

In analyzing Daw Khin Myo Chit's short stories, depending on the titles and background of short stories, the number of males and females differ significantly in each story. In some stories there is bias towards males while some have bias towards the females. However, by overall representation, it can be found that the number of males and females involved in the stories are nearly the same and there is no significant difference between them except females' frequency is inconsiderably lower than males'. In the collection of Ma Thanegi's translated works, there are various kinds of short stories written originally in Myanmar by many authors. They have different themes and the plots are created in different ways. According to the titles and background of different short stories, the involvement of the number of males and females is different in each story. In some stories, men are invisible and in some stories, women are invisible and non-recogonized. However, in overall representation, the result shows that there is no difference in the involvement of males and females in the short stories although males' frequency is slightly lower than females'. Therefore it is observed that there is no significant difference between males and females in characters by sex both in Daw Khin Myo Chit's short stories and in Ma Thanegi's translated works.

\subsection{Occupational Roles}

Occupations assigned to males and females are counted to see how many males and females occupy what proportion of the occupations appeared in the stories. In Daw Khin Myo Chit's short stories, in comparing number of female characters with male characters, there are many occupations in which men are represented. There is the highest bias towards the males. These occupations range from traditional jobs carried out by men such as - "craft men, headman, rebel insurgent, Sayardaw (the head of monk), chauffeur, leader, master, maestro, owner, murderer, manipulator, astrologer, lawyer, householder, puppet maker, hermit, caravaner, robber, thief and mendicant, handyman, broker, diplomat, owner of diamond, officer, monks, soldier, sentry, shopkeeper, trader, guard, vegetable seller, police, workmen, miller, prisoner, goldsmith, master, merchants" which represent men are described as higher economic than women and they can lead the life more than the women.

There are a few occupations such as "dancer and school mistress, customer, business career, servant, fish-women, nun, housewife, maid, shopkeeper, slave" in which women are represented. That is why women are represented as lower position than men and they are submissive and followers according to most of occupations assigned to females. The occupations such as "government servant, teacher, lawyer, astrologer, writer, servant' can be found in both males and females. In the short stories written by Daw Khin Myo Chit, males significantly outnumber females.

In Ma Thanegi's translated works, the occupations for males are mostly higher than the occupations assigned to females. There is the highest bias towards the males. These occupations range from traditional jobs carried out by men such as - "monks, traditional doctor, businessman, clerk, executive, driver, director, headman, judge, chairman, supporter, gold shop owner, officer, postman, restaurant owner, video shop owner, car owner, TV owner, pensioner, executive, salesman, master mariner, owner of industries, waiter, mason, photographer, worker, monks, village elders, leader of village, novice, water seller, abbot, movie director". Most of the occupations concerned with the males have high status and show that men can lead the life more than the women and they are self-serving and proud. Some of the occupations such as "carpenter, fisherman, ferryman, trishaw driver, night-watchman, puppet singer, waiter, mason, beggar, water-seller" are lower status for men. However, the men are brave and independent, and they earn money for their family by doing various kinds of jobs whether they are higher rank or lower ranks as men are the heads of the whole family. Some occupations such as "school 
teacher, writer, dancer, painter" are referred to both males and females. But the frequency of teacher which refers to the males is higher than that of females.

The occupations assigned to females are "maid, washwomen, supermarket, seamstress, actress, vendor, flower bearer" which indicate low status, except "teacher, supermarket owner, pickled tea owner, actress, nun, make up artist" in which women are represented as high status. Also in the collection of short stories translated by Ma Thanegi, males significantly outnumber females in the occupations.

It is found in both of the books that the occupations assigned to males are higher than that of the females and there is discrimination between males and females. It is believed in Myanmar that only the men have to get the job to take care of the family as father is the head of the whole family. The women are dependent on their husband's income. The number of occupation that represents the females is invisible. The results describe that men have higher career status and being more intellectual than women.

\subsection{Roles of Activities}

Analysing the activities assigned to males and females is also one of the factors to be considered in gender representation. In most of gender-biased materials, females are shown to be engaged only in domestic tasks. In this dissertation, there are many activities assigned to females as males.

In the short stories written by Daw Khin Myo Chit, in most of short stories there are many roles the women carry out. Some examples of the activities assigned to males are "laboring, hunting, helping others, robbing, taking away the people who have diseases," which convey that men are physically strong and brave. The activities such as "playing, guiding, climbing trees, creating, making judgment, driving, suggesting, earning money, warning, admonishing, showing the ability, swimming, taking care the family, sailing, serving the country, ordering, travelling" which are in the traditional way and indicate that as the masculine trait, men are leaders, problem solvers, perpetrators, independent and proud. Some activities as "killing the princes, attacking, smoking, making mischief" convey the negative connotation that men are aggressive. However, non-traditional activities such as "nurturing, serving, doing domestic works, selling" are assigned to males as they do sometimes like the women.

The activities assigned to females are "domestic work, serving, picking flowers, nurturing, doing something secretly, and helping others, shopping, making yataya (to reduce bad luck), nurturing, offering alms, learning, being attacked, leaving attacked, destroying the jewels, giving up the jewels, asking her husband to do, praying" which are in the traditional way. Therefore women can be said that they are submissive, dependent, helpful, followers and ask for helps and accept the other's advises easily. But it can also be found non-traditional activities of female such as "adventuring, laboring, smoking, solving the problems" which are masculine traits. This fact points out that the woman comes abreast of the man that women are also active and assertive. In spite of being a woman, she can do like the man. In the activities such as "helping, travelling, playing, serving, welcoming and religious activities, driving, walking, taking leisure time, leading, paying respect to the elders, teaching, writing, reading, quarrelling”, both genders can be found. Therefore, it can be said in Daw Khin Myo Chit's short stories that there is no difference in the activities assigned to males and females.

In analyzing each story in Ma Thanegi's translated works, some examples of the activities assigned to males are "fishing, smoking, drinking alcohol, betting, addressing arguments, putting on complaining, quarrelling" which convey the negative activities while there are also positive activities like "helping others, earning money, collecting books, religious activities, travelling, studying, teaching, composing poems, drawing, consoling, negotiating, rowing the boats, driving the carts, asking helps, selling, consulting, guiding, attacking giants, scolding the kids, threatening, walking,being religious, doing business, writing, pedaling, offering helps, earning money, bargaining, giving, playing the flute, singing, saving the people, forming the rafts, comforting, fishing and ferrying," which are done by the males. It can be said that men are physically strong, independent, brave and aggressive. Moreover, they are self-serving, problem solvers and leaders. And also "nurturing" and "domestic" activities are sometimes carried out by the men as the non-traditional activities assigned to males.

The activities assigned to females are "domestic work, nurturing, religious activity, shopping, sewing, travelling, praying, tried out make up, asking helps, selling, bargaining, doing chores, singing, serving the guests, praising, admonishing, consoling, being religious, doing merit, helping, borrowing" show that women can do many activities which are positive ones. Moreover, it can be said that women are physically weak, physically attractive, submissive, followers and they use to ask for advises. On the other hand, they are independent, active, problem solvers and leader like the men such in the activities as, "negotiating, doing business, earning money, gathering firewood and farming". And also there are activities which convey negatively such as "inquisitive, complaining, quarrelling, playing cards, puffing cheroot, swearing, screaming, and gossiping". Also in Ma Thanegi's 
translated works, there is no significant difference between males and females in the activities of overall stories although there is a slightly higher percentage in females' activities than males'.

Therefore, men and women follow the traditional activities of masculinity and femininity in some cases sometimes they challenge the traditional activities. Although a number of activities done by the females are nearly the same to that of the activities done by males, most of the activities assigned to males are assertive, independent, self-serving, and brave whereas most of the activities assigned to females are submissive, dependent and nurturing except a few are active and independent. It is found also in the activities assigned to males and females in the two books that there is no significant difference between males and females except inconsiderable differences. So it can be said that the women are not always subordinate and they can also share the work to do like the men. Women have freedom to do what they like. Sometimes they do assume that this has to be done by man or that has to be done by woman, and sometimes they do not classify what the men have to do or what the women have to do. As the time pass, there is lower discrimination between males and females.

\subsection{Stereotypes of Males and Females}

In considering the stereotypes of males and females representation from the selected short stories, the first category includes career option and division in which the number of males is much more than females. Males are described as higher economics; they have the career status and are intellectual. In this category, it is found that women are inferior and men are superior both in Daw Khin Myo Chit's short stories and in Ma Thanegi's translated works. Males significantly outnumber the females in this category. Males have much more careers than females and they have more opportunities to get the jobs than females.

The second category is a. aggressive and $b$. nurturing. In the aggressive, the number of males is higher than that of females in Daw Khin Myo Chit's short stories: that is because in some stories depending on the plot, it can be found that the behaviours of males are in trading way, they are ready to attack and they behave in a very determined and forceful way to succeed what they have to do and women are followers in most of her stories. Of course, in Myanmar culture, most of the women are not aggressive and assertive except having a few. But in Ma Thanegi's translated works, the frequency of the males and females are nearly the same and they have the same percentage in the aggressive behavior. Because, in some of the stories of her translated works, women have to lead their life and so they have to attack in some ways to get what they want to be. In contrast, in the nurturing, the number of females is significantly higher than men in Ma Thangi's translated works rather than Daw Khin Myo Chit's stories. Therefore it can be said that most of women have mother spirit and so in most of short stories, women are found taking care of some others or some animals, helping the others to be successful in something and encouraging somebody to develop and uplift his/ her life. A few numbers of males in this category are also found such as in "taking-care of their children, doing domestic works and nurturing". In most of the cases form the two books of collection of short stories, it is found that men are more active than women while women nurture more than men.

The third category is a. active behaviour and b. passive behavior. In the active behavior, the number of males is mostly higher than that of females in both of the books. There is highest bias to the males. In the active behavior, men are independent and they can do many things themselves to reach the success at the end. And they can create the new things and they can make the decision very well. So they are so proud, they feel self-confident and assertive. They rely on themselves. On the other hand, the women depend on men in most of the cases. But, in a few cases, most of the women have to do themselves and they are self-serving like the men, for example "they dug small well to get water, fetch water, they work to get income, they had new experience, they are free, they lead their life, they solve the problem themselves and so on". In the passive category, the number of females is more than the number of males. The frequency of females in Ma Thanegi's translated works is higher than that in Daw Khin Myo Chit's stories although the number of female is more than that of males in passive behavior of the two books. That is because, in some events, women are followers and they have to be silent not to dare to attack the men because of the physical weakness; that is submissive. Most of the women rely on others including men in most of the situations. Surprisingly, passive behaviour can also be found in the males. That is because, in the background of some stories, even though being males, they have to depend on others in some cases, that is it does not mean they depend on women, but depend on any other men in some situations.

The fourth category is a. indoor location and b. outdoor location. In indoor location, the number of females is higher than that of the males. In Myanmar culture, women are mostly used to be in indoor location and they have to do some affairs in doors. In contrast, in the outside location, the number of males is more than the number of females. Most of men used to enjoy to be in outside for job, social affair, and travelling more than staying indoor. The result in this category is also same in the two books of selected short stories. 
The fifth category is a. helping behavior and b. being helped behaviour. Both in Daw Khin Myo Chit's short stories and in Ma Thanegi's translated works, it is found that in "helping" category, the number of males is higher than that of females. But in "being helped", the number of females is significantly higher than that of the males because woman asks more helps and man seldom asks helps to others. A man used to solve the problems themselves and woman is troublesome. Women can be found that they are dependent and subordinate. It can be said that men are helpful and independent. Women are submissive and they depend on men rather than men rely on others. The man gives helps and advices, in the contrast the woman has to ask for helps.

The last category is "emotion". Also in this category, both the males and females have more emotion. But the women have to feel more than the men in the two books. The kind of emotion is different. Most of the emotions in males are "anger, disgust, and contempt" which convey the aggressive and negative connotation while the emotions of females are "fear, shyness, sadness and beloved" which mean submissive. As the characters are human beings, they have different kinds of emotions. From this category, the usages found show that women are more emotional than men.

Therefore, it can be concluded that in the two books of short stories written originally in English and written originally in Myanmar, the results found are not significantly different and the findings are nearly the same. In both of the books, although there are imbalances between men and women in a few situations such as in occupational roles, it is obvious form many more balanced situation that males and females representation is seen as equality.

\section{Conclusion}

The results show that gender roles arising from Myanmar culture prevent women from enjoying their rights to personal safety, education, employment, freedom of movement, and participation in leadership, recreation and community activities. In the occupation, it is found that the occupations assigned to females are lower than that of males and most of the occupations that refer to females have low status compared to the men. However they, of course, have to take more activities as men. Women are major roles in doing social roles and religion. Chit (2006) states that Myanmar women are independent and are not subject to control.They feel satisfied in doing like that they give more favour to their husband and their son. Chit continues that most of the women are raised to think that their greatest wish is to become dutiful wives of their husbands and that they have the duty to do the housework and to look after their children. As women are the protector of tradition, in Myanmar, the women are expected to take more responsibilities in doing in family affair and social affair except making the important decision in some cases. In Myanmar culture, it is accepted that men have to go outside for family income and women have to be in doors to take the responsibilities of the house. The results show that women are subordinate and inferior comparing with men although there is law that men and women can enjoy equal right. It is found that women have to carry out the primary position in doing many activities although they are always placed in the second position. Therefore, from studying Myanmar literary works, it can be known that women are in breast with the men although there is discrimination in some cases because of Myanmar tradition and culture. However, the results provide some insight as to the representation of males and females in Myanmar culture through only short stories. So it cannot be certain that the findings are generalizable to reflect Myanmar aunthetic culture. Therefore, to get exact information of male and female representation to reflect Myanmar culture, it is needed to analyze other medias such as Myanmar movies and Myanmar novels as further studies. Moreover, another study should be considered to conduct contrastive analysis of gender representation in fictions written by Myanmar writers and foreign writers.

\section{Acknowledgments}

I would like to thank Prof. Dr Chaiyathip Katsura, my supervisor, for his invaluable suggestions and excellent comments on the earlier research on Myanmar short stories which this paper is based. I also thank Prof. Ni Ni Hlaing, Mandalay University of Distance Education, Republic of the Union of Myanmar, for her kind support to edit my paper.

\section{References}

Belak, B. (2002). Gathering strength: Women from Burma on their rights: Images Asia. Retrived from http://www.ibiblio.org/obl/docs/GS01a.pdf

Chit, D. K. M. (2004). Her infinite variety and other stories. Parami Bookshop, Yangon, Myanmar.

Chit, D. K. M. (2006). Female. Bahan township, Yangon, Myanmar: Zun Pwint Press.

Daw, K. M. C. (2005). 13 Carat diamond and other stories (2nd ed.). Parami Bookshop. 
DFID Myanmar operational plan 2011 -gender annex. (2011). Retrieved from https://www.gov.uk/government/ uploads/system/uploads/attachment_data/file/67322/burma-2011-summary.pdf

Helleis, L. D. (2004). Differentiation of gender roles and sex frequency in children's literature. (Doctoral dissertation, Maimonides University). Retrived from http://www.esextherapy.com/dissertations/Leslie\% 20Dawn $\% 20$ Helleis\%20Differentiation\%20of\%20Gender\%20Roles\%20And $\% 20$ Sex $\% 20$ Frequency $\% 20$ in \%20Children's\%20Literature.pdf

Ho, T. C. (2011). Representing Burma: Narrative displacement and gender. PMLA, 126(3), 662-671.

Information about variable and data sources for 2014 SIGI. (2015). Retrieved from http://www.genderindex.org/ country/myanmar

Interim country partnership strategy, Myanmar. (2012-2014). Gender analysis. Retrieved from http://www.adb.org/sites/default/files/linked-documents/icps-mya-2012-2014-ga.pdf

Khurshid, K., Gillani, I. G., \& Hashmi, M. A. (2010). A study of the representation of female image in the textbooks of English and Urdu at secondary school level. Pakistan Journal of Social Sciences, 30(2), 425. Retrived from http://www.bzu.edu.pk/PJSS/Vol30No22010/Final_PJSS-30-2-18.pdf

Legal Issues on Myanmar Journal. (2011, August). volume 9.

MacArthur, H., \& Poulin, C. (2011). Gender Representation in a Selection of Children's Picture Books: A Skewed Ratio of Male to Female Characters? Undergraduate Research Journal for the Human Sciences, 10(1). Retrieved from https://www.kon.org/urc/v10/macarthur.html

Minn, A. M. (2014). Interviewing with Executive Director U Aung Myo Minn from Equality Myanmar. Kumudra Journal, 3, 12.

Ottosson, T., \& Cheng, X. (2012). The representation of gender roles in the media: an analysis of gender discourse in Sex and the City movies (Bachelor's thesis in Political Science 15 ECTS). Department of Economics and Informatics, University West (P-15)

Paynter, K. C. (2011). Gender stereotypes and representation of female characters in children's picture books. (Doctoral dissertation, Liberty University). Retrieved from http://digitalcommons.liberty.edu/cgi/ viewcontent.cgi?article $=1500 \&$ context $=$ doctoral

Thanegi, M. (2009). Selected Myanmar short stories. Yangon, Myanmar: UNITY Publishing House.

Thein, P. T. (2015). Gender equality and cultural norms in Myanmar. Paper presented at the International conference on Myanmar studies, Chiang Mai University, Thailand.

\section{Copyrights}

Copyright for this article is retained by the author(s), with first publication rights granted to the journal.

This is an open-access article distributed under the terms and conditions of the Creative Commons Attribution license (http://creativecommons.org/licenses/by/3.0/). 